\title{
A Síndrome de Ulisses ou a doença da memória em Santiago Gamboa
}

\author{
El Síndrome de Ulises o la enfermedad de la memoria en Santiago Gamboa
}

\section{Luiza Santana Chaves Cléudia de Sousa Jardim}

Universidade Federal de Minas Gerais - UFMG - Belo Horizonte - Minas Gerais - Brasil

Resumo: Apresentamos neste artigo uma reflexão sobre a diáspora contemporânea na obra El Síndrome de Ulises (2005) do escritor colombiano Santiago Gamboa, comentando principalmente as diferenças entre a imigração e o exílio, figuradas na narrativa pelas personagens do colombiano Esteban e do coreano Jung. Analisamos o lugar da enunciação hispano-americana no panorama literário universal a partir dos embates entre local / global em meio ao que Santiago Gamboa demonstra ser as vivências dos "Ulisses" contemporâneos, seres invisíveis, sobrevivendo em sociedades prósperas que os ignoram das mais diferentes formas. El Síndrome de Ulises é, pois, um romance ficcional construído em torno dos fenômenos diaspóricos contemporâneos e dos conflitos identitários surgidos em decorrência desses deslocamentos.

Palavras-chave: Literatura hispano-americana. Diáspora. Memória. Identidade.

Resumen: Presentamos en este artículo una reflexión sobre la diáspora contemporánea en la obra El Síndrome de Ulises (2005) del escritor colombiano Santiago Gamboa, comentando sobre todo las diferencias entre la inmigración y el exilio, conceptos figurados en la narrativa por los personajes del colombiano Esteban y del coreano Jung. Analizamos el lugar de la enunciación hispanoamericana en el panorama literario universal a partir de los enfrentamientos entre local / global en el medio de lo que Santiago Gamboa demuestra ser las experiencias de los "Ulises", seres invisibles, sobreviviendo en las sociedades prósperas que los ignoran de las más diferentes maneras. El Síndrome de Ulises es, pues, una novela ficcional sobre los fenómenos diaspóricos y los conflitos identitarios que han surgido como resultado de estos desplazamientos.

Palabras-clave: Literatura hispanoamericana. Diáspora. Memoria. Identidad. 
Solo voy con mi pena / Sola va mi condena / Correr es mi destino / Para burlar la ley... / Perdido en el corazón / De la grande babylon / Me dicen el clandestino / Por no llevar papel... / Soy una raya en el mar / Fantasma en la ciudad / Mi vida va prohibida / Dice la autoridad

(Clandestino, Mano Chao)

Buscando visa para un sueño / Buscando visa, la razón de ser / Buscando visa, para no volver / Buscando visa, la necesidad / Buscando visa, para naufragar / Buscando visa, carne de la mar

(Visa para un sueño, Juan Luis Guerra)

\section{Introdução: que síndrome é essa?}

Apresentamos neste artigo uma reflexão sobre a diáspora contemporânea descrita na obra El Síndrome de Ulises (2005) do escritor colombiano, Santiago Gamboa. Nessa narrativa, o autor trabalha bastante com os temas relacionados ao lugar da enunciação hispano-americana no panorama literário universal, bem como busca incitar uma reflexão acerca dos embates entre local / global em meio ao que Gamboa demonstra ser as vivências / experiências dos "Ulisses" contemporâneos, aqueles seres invisíveis, sobrevivendo em sociedades prósperas que os ignoram das mais diferentes formas. Sua obra El Síndrome de Ulises é, pois, uma ficção construída em torno dos fenômenos diaspóricos da globalização e dos conflitos de identidade surgidos em decorrência desses deslocamentos.

O autor nos apresenta a "cidade luz" (Paris) com outra cara ao enfocar personagens que se concentram nos guetos, nos recônditos periféricos parisienses. Personagens angustiados que enfrentam uma sociedade fria $\mathrm{e}$ indiferente, povoada por imigrantes ilegais de várias partes do mundo, entre os quais se incluem refugiados ou fugitivos políticos, imigrantes legais e ilegais, que sofrem a dor da solidão, a nostalgia, o estresse e o temor ao fracasso na nova "terra" (estrangeira no sentido mais assustador do termo).

O romance de Gamboa se divide em três grandes capítulos: "Historias de Fantasmas", "Inmigrantes \& Co" e "El síndrome de Ulises". Todos eles se entretecem de forma a definir um panorama das características que conformam o ambiente opressivo de uma Paris imersa às consequências da imigração contemporânea. Podemos destacar na trama alguns termos-chave, que definiriam seu complexo enredo: as noções atuais de pátria, língua e cultura nascidas com a diáspora, nos remetendo ao que Sônia Torres (2011) afirma ser uma das características fundamentais do mundo contemporâneo, isto é, "o fato de ele ter produzido mais refugiados, emigrantes e exilados do que qualquer outra época da história" (TORRES, 2001, p. 11).

Nesta história de viagem sem retorno, em que o escritor Gamboa apresenta a questão da perda de laços de identidade que trazem frustrações para seus personagens, é possível fazer um questionamento sobre a fantasmagoria da imigração. Os personagens da obra são sujeitos não reconhecidos pela sociedade, em sua maioria hispano-americanos. São indivíduos desconsiderados (veladamente ou explicitamente) pelo país que eles elegeram para viver, que não dá lugar à sua realização pessoal, nem a oportunidade de serem cidadãos plenos. Isso vai de encontro com as reflexões de Edward Said (2003), que afirma ser o exílio "uma condição criada para negar a dignidade e a identidade das pessoas" (SAID, 2003, p. 48).

Esse sentimento de perda identitária remete a um outro sentimento mais profundo: a melancolia produzida pela saudade da pátria. Imigrar para a Europa sempre foi, desde outras épocas, um sonho a se realizar. Porém, esse sonho sempre ocorreu em meio à uma difícil condição: a negação de vistos de permanência, a ilegalidade. Nas três últimas décadas, foi possível observar um processo em que milhões de pessoas saíram de seu país em busca de um futuro melhor, a tal ponto disso ter se transformado em um fator de risco (considerado um enorme problema em muitos países "de destino" de imigração). No entanto, pouco se pensa na condição sub-humana às quais são submetidos esses sujeitos diaspóricos: os imigrantes se expõem a diferentes e intensos níveis de estresse, o que os torna candidatos a padecer a chamada enfermidade da nostalgia, "el síndrome del 
inmigrante com estrés crónico y múltiple" (ACHOTEGUI, 2008, p. 1), mais conhecida como "el síndrome de Ulises", nome que intitula o romance em estudo.

\section{Diásporas dos muitos “Ulisses": identidade e memória}

Sobre o quadro clínico dessa doença do exílio, deslocamento ou diáspora, o psiquiatra Joseba Achotegui (2008) comenta que, na maioria dos casos, a pessoa padece de dores oriundas de um estresse superior a sua capacidade de adaptação. Quadro clínico grave que desperta sérias preocupações, pois se tornou um problema de saúde que afeta grande parte dos imigrantes ilegais, em razão das injustas condições vivenciadas em um ambiente desconhecido e, muitas vezes, hostil, tal como descrito na seguinte passagem do romance El Síndrome de Ulises: "Los que habíamos llegado por la puerta de atrás, sorteando las basuras, vivíamos mucho peor que los insectos y las ratas" (GAMBOA, 2004, p. 11).

$\mathrm{Na}$ obra de Gamboa, vemos transportados à literatura os sintomas dessa síndrome, que se dá em circunstâncias de um alto estresse quando o ser humano vive em contínuo deslocamento bem como em um exílio sofrido, traumático: "No había nada, o casi nada, para nosotros, y por eso nos alimentábamos de absurdos deseos. Todas nuestras frases comenzaban así: 'Cuando sea...' (GAMBOA, 2004, p. 11). Essa enfermidade, segundo Achotegui (2008) é própria dos imigrantes, sobretudo dos ilegais, que enfrentam precárias condições de vida, quando o nível de estresse é altíssimo e aparecem sintomas crônicos de angústia, solidão, sentimento perpétuo de medo, de fracasso e de perseguição.

Angústia por não poder trazer a sua família para perto de si; sentimento de fracasso por não ter possibilidades de ascender no mercado de trabalho e por não querer voltar ao lugar de origem com as "mãos vazias"; sentimento de medo, por estar muitas vezes vinculado às máfias de imigração ilegal. É uma luta diária pela sobrevivência que, somada à solidão (pelo isolamento da família e, muitas vezes, por não saberem se comunicar na língua estrangeira), se transforma em uma forte depressão que vai minando lentamente as esperanças de melhoria de vida e pode ser converter em uma crise crônica (uma síndrome).

Esses sentimentos de imensa nostalgia e de sensação de estrangeria frente ao novo podem ser verificados no herói grego Ulisses (ou Odisseu), protagonista da Odisséia, obra épica que narra a viagem de retorno de Ulisses à Ítaca. O herói luta na guerra de Tróia, vive grande parte de sua vida longe da família e de sua pátria, atravessa um mundo fabuloso, vencendo ou caindo em seduções e armadilhas, sente solidão, dores e passa por perigos imensos, sempre na condição de um sujeito deslocado e em deslocamento. Transforma-se, no decorrer da epopeia, em um homem sofrido que logra regressar a sua terra natal somente após quase 20 anos da sua partida.

Pode-se perceber que a memória constitui um elemento essencial na formação da identidade do "imigrante" grego Ulisses; neste sentido, lembramos a seguinte constatação de Stuart Hall (2004): "as identidades nacionais não são coisas com as quais nós nascemos, mas são formadas, transformadas no interior da representação" (HALL, 2004, p. 48). Sendo a nação construída, logo existe uma profunda ligação entre memória e identidade que gera sentimentos histórico-culturais e serve de "alimento" identitário para este povo. Nas palavras de Angel Castiñeira (2005): "no hay identidad sin memoria y no hay memoria sin inteligencia, es decir, sin trabajo de la conciencia [...]; memoria y conciencia son una sola y misma cosa" (CASTIÑEIRA, 2005, p. 59).

A identidade pessoal, como uma construção narrativa dinâmica e múltipla que necessita de uma continuidade temporal e de um relacionamento dialógico com o outro, esse também, ao mesmo tempo, uno e diverso, ganha amplitude coletiva quando alcança a autoconsciência de grupo, fato que derivaria o sentimento de "identidade nacional". Assim, Ulisses, como um exilado, conserva na memória individual, a possibilidade de manter a tradição e a cultura que o liga a seu povo de origem. 
O impulso de auto conservação que nasce do medo mítico de perder "o eu" (isto é, de perder a ligação identitária com o passado) se manifesta em Ulisses em todas as circunstâncias que o afastam do seu objetivo de retorno ao lar. No entanto, no caso da síndrome em questão, a nostalgia e o medo não são superados, se tornam uma doença crônica, que definha as faculdades físicas e emocionais do sujeito, levando, em casos extremos, ao suicídio.

A história do herói grego que inspirou o nome da síndrome do imigrante, também inspirou, por sua vez, o escritor Santiago Gamboa a refletir sobre o que ocorre com os imigrantes dos nossos tempos. Esses personagens que peregrinam para outras terras, que vão se enriquecendo com as experiências da viagem, sofrendo inúmeros traumas, privações e humilhações em busca do sonho das "terras prometidas", e que, como o Ulisses da Odisséia, têm o poder de converter sua viagem em relatos que vão sendo incorporados no grande arsenal da memória cultural contemporânea. Essas vivências fazem parte das memórias individuais e, juntas, criam redes de memórias coletivas, uma vez que os sujeitos estão inseridos num grupo.

Segundo Hugo Achugar (2006), "a avaliação do passado é central na construção da memória coletiva e, sobretudo, no planejamento das políticas de tal memória" (ACHUGAR, 2006, p. 222); assim o processo de negociação discursiva entre as memórias individuais e as memórias coletivas "se constitui no campo de batalha, onde o presente debate o passado como um modo de construir o futuro" (ACHUGAR, 2006, p. 223). O sentimento de vínculo identitário nasce, então, da sensação de coesão percebida por meio do repertório compartilhado de crenças, conduta, símbolos, estilos de vida e valores que norteiam maneiras de pensar, perceber e sentir. O sujeito em diáspora se encontra no entre-lugar, isto é, pertence e não pertence, ao mesmo tempo e de igual maneira, a dois lugares distintos. Sua identidade está fragmentada e deslocada, levando-nos a questionar, perplexamente, em conjunção com Stuart Hall (2004): "como podemos conceber ou imaginar a identidade, a diferença e o pertencimento, após a diáspora?" (HALL, 2004, p. 17). Hall (2004) prossegue sua indagação: "já que 'a identidade cultural' carrega consigo tantos tragos de unidade essencial, unicidade primordial, indivisibilidade e mesmice, como devemos 'pensar' as identidades inscritas nas relações de poder, construídas pela diferença, e disjuntura?" (HALL, 2004, p. 17).

Faz-se, portanto, necessário pensar nos caminhos entre individual e universal que se entrecruzam na condição diaspórica, de forma a solicitar a abstenção de uma utópica harmonização das diferenças que surge a partir da problematização dos espaços. Nesse sentido, a obra El Síndrome de Ulisses (2005), com sua narrativa de diásporas individuais, parece deixar ecoar: como uma experiência / uma vivência particular pode chegar a revestir-se como memória coletiva?

De acordo com Laclau (1996), "o universal é parte da minha identidade na medida em que estou penetrado por uma falta constitutiva, ou seja, na medida em que minha identidade diferencial tem fracassado parcialmente em seu processo de constituição" (LACLAU, 1996, p. 56). O universal emerge, então, do particular não como um princípio que o explicaria, mas como um "um horizonte incompleto que sutura uma identidade particular deslocada" (LACLAU, 1996, p. 56). A nosso ver, a narrativa diaspórica de Santiago Gamboa, aqui analisada, toca no fato de que a identidade não é plenamente constituída fora de um contexto coletivo, universal que a englobe. Isto quer dizer que há reivindicações (individuais e coletivas) insatisfeitas (referentes ao acesso aos direitos humanos, por exemplo) que não podem ser constituídas em termos de diferença (o nativo versus o imigrante, o legal versus o ilegal, o igual versus o diferente, etc.), mas de certos princípios universais que os grupos excluídos compartilham com o restante da comunidade (sonhos, aspirações, valores humanitários). 


\section{Esteban e Jung: perfis diferentes de imigrantes}

No romance El Síndrome de Ulises de Santiago Gamboa há vários personagens vivendo em condição de diáspora na cidade de Paris. Neste artigo, nos deteremos nos personagens de Esteban, o narrador-protagonista - um estudante de doutorado colombiano, e de Jung - um coreano, lavador de pratos, personagem secundária, porém, um dos maiores exemplos na obra da enfermidade "síndrome de Ulisses". Como comenta Santiago Gamboa (2005), em uma entrevista ao jornal La Nación, a descrição de Paris na sua obra em nada se parece àquela anunciada em pacotes turísticos: "París no era la ciudad de los sueños bohemios del artista ni la de los sueños románticos de un escritor" (GAMBOA apud REINOSO, 2005, s.p.). Ao contrário, a capital francesa é retratada no livro em sua face suburbana e periférica: "Era una ciudad de barriadas, de suburbios de inmigrantes. Las cosas bonitas de la ciudad no se nombran en el libro porque, de hecho, para los inmigrantes no existen" (GAMBOA apud REINOSO, 2005, s.p.).

Esteban e Jung encontram-se em uma Paris que é sinônimo de hostilidade, tristeza e opressão. Os espaços são povoados pela angústia, pela solidão e pela saudade e os encontros com outros imigrantes se convertem em ocasião para "compartir las quejas sobre lo difícil que es sobrevivir en esta ciudad, el deseo de estar en otra parte donde haga sol y la vida sea más feliz" (GAMBOA, 2004, p. 246). Esteban é um jovem escritor colombiano que sai em busca do seu sonho de fazer carreira na cidade de Paris, lugar mítico para a literatura, onde viveram grandes escritores latino-americanos, tais como: Rubén Darío, Mario Vargas Llosa, Miguel Ángel Astúrias, entre outros. Possui uma bolsa de estudos em Literatura na Universidade de Sorbone, a qual Ihe permite viver como cidadão legal, apesar das condições precárias e de testemunhar os sintomas dos colegas imigrantes que padecem enfermos da Síndrome de Ulisses. Comenta o protagonista que a grande preocupação de todos os que chegam a Paris é encontrar um lugar para viverem e esse foi o seu maior problema antes de encontrar o lugar no qual vive, descrevendo-o como uma "pocilga" (GAMBOA, 2004, p. 15). O narrador personagem também relata que:

La comunidad colombiana de París funciona como un ghetto en el que todo se sabe y, cuando digo comunidad, me refiero a los exiliados económicos o políticos, los que llegaron com dos cajas de cartón y un maletín de tela, cruzando la frontera francesa desde España en el baúl de un carro en la carga de un camión, ateridos de frío y con el fajo de billetes entre los calzoncillos. (GAMBOA, 2004, p. 25)

As moradias de extensão mínima, sem janelas e sem banheiros funcionam como recintos fechados, que impossibilitam um entorno social em que o individuo dê vazão à sua identidade, aos seus costumes e, com isso, possa interagir com os demais. Para tentar melhorar essas condições miseráveis, Esteban busca trabalho em um restaurante coreano como lavador de pratos, além de ser professor de espanhol em uma academia de línguas. Afirma que, mesmo em dificuldades, via Paris como uma "ciudad voluptuosa y llena de gente próspera, aunque ése no fuera mi caso" (GAMBOA, 2004, p.11). O protagonista se sente num caos que, ao mesmo tempo, o deslumbra e o agride, pois sempre se iludiu com uma vida melhor na Europa e se põe a lamentar: "[...] maldigo no haber optado por otra ciudad, un lugar en el que hiciera menos frío y donde la gente fuera menos dura" (GAMBOA, 2004, p. 15).

O caso de Jung, companheiro de Esteban nos serviços do restaurante, serve de contraponto para a situação de legalidade no país vivida pelo narradorprotagonista. $O$ imigrante coreano sofre com uma dolorosa história de amor em consequência de uma separação forçada e padece gradualmente os sintomas da síndrome de Ulisses, se encaixando perfeitamente na afirmação de Said (2003) de que exilado está fadado ao desassossego, vive na condição de estar totalmente deslocado, é o fora de lugar. O exilado vive essa nostalgia sem fim que, segundo Paul Ricœur (2000), é "memoria herida, incluso enferma. Lo demuestran expresiones corrientes como traumatismo, herida, cicatrices, 
etcétera" (RICCEUR, 2000, p. 96), terminando por se convergir em um fragmento da pátria natal que se desgarrou do todo. Nesse sentido, é preciso lembrar a diferenciação feita por Edward Said (2003) entre exílio e imigração, já que o exilado não pode regressar.

Jung, por ser oriundo de uma cultura em que as relações familiares são mais rígidas e os vínculos de solidariedade são mais fortes, se assusta muito ao enfrentar a sociedade europeia, onde os vínculos são mais distantes, ainda mais se tratando de um imigrante ilegal: "cuando uno es tan poca cosa para los demás tiende a cuidarse", (GAMBOA, 2004, p. 56), já que "cualquier día una mano puede agarrarme del hombro y detenerme" (GAMBOA, 2004, p. 56). A solidão passa a fazer parte de sua vida com muita intensidade e o personagem comenta: "Qué ironía de la vida. Llegar hasta acá, con el trabajo que me costó, y acabar siendo explotado por otro coreano" (GAMBOA, 2005, p. 54). Jung explica ao narrador que sua história não é muito diferente da de outros compatriotas coreanos. Ele emigrou porque queria que a vida lhe desse prazer, sonhava, enfim, com uma vida melhor. Havia se casado com uma jovem chamada Min Lin e os dois tiveram uma filha que morreu de desnutrição e cegueira aos sete anos. Sua esposa teve depressão e tentou suicidar-se, no entanto na Coreia do Norte o suicídio é proibido e punido por lei. Jung perdeu o trabalho e decidiu fugir de seu do país.

Advém daí a outra diferença grande entre Esteban e Jung, além da ilegalidade de sua estadia em Paris, Jung é mais que um imigrante, é um exilado, isto é, Jung não pode mais voltar para seu país. Além de ter que conviver com a solidão de se adaptar à língua e à cultura num terreno desconhecido e, muitas vezes, hostil, o coreano não tem perspectivas de regresso. Confuso entre a identidade deixada para trás e a nova, construída por força das circunstâncias, Jung converte-se, como mesmo se descreve, em um ser fragmentado, sem laços identitários e/ou afetivos que o vinculem à cidade na qual habita e, por isso, não consegue se adaptar e se ver livre da dor ao lembrar da sua pátria e da sua família.

O narrador comenta que, tal como Jung, ele e outros imigrantes passam por momentos de extrema angústia. No entanto, Jung se isolava. Não fazia como os outros que ao serem acometidos pela angústia, geralmente no meio da noite, saiam para encontrar-se nos bares ou nas moradias de outros imigrantes, as quais funcionam como locais de memória, onde afloravam as recordações de suas pátrias, as pessoas se consolavam, compartilhavam suas tristezas e, de certa forma, renovavam as esperanças de seguir lutando na França, já que amenizavam o sentimento de solidão. Vivendo isolado em meio a um ambiente melancólico, o medo e a insegurança se apoderam de Jung provocandoIhe uma profunda depressão. Somando-se a isso os traumas causados pelos perigos vividos em sua viagem migratória, que também contribuíram significativamente para Jung ser extremamente paranoico e desconfiado. Além disso, a saída do seu país em uma situação ilegal, levou-o a se sentir fracassado.

$\mathrm{Na}$ tentativa de seguir vivo e de se defender das humilhações longe do seu país, Jung vive rememorando a sua terra, está sempre se auto narrando, e esta compulsão de memória-recordação contínua, ao invés de o libertar, o afunda cada vez mais, fazendo-o sobreviver de um passado mítico, idealizado, transformado em um lugar que não existe, enfim, em uma terra idílica que dificilmente será superada por qualquer outro lugar no qual venha a morar. Jung é descrito como "un hombre solitario y sin documentos legales con tres hospitalizaciones recientes por ataques de tipo epiléptico, pérdida del conocimiento y del sentido de la realidad, Dolores abdominales y delírios" (GAMBOA, 2004, p. 350).

Esta condição de sujeito invisível / invisibilizado detona em Jung uma total perda de autoestima e de consciência dos próprios direitos, de sua dignidade humana. Jung vive no automatismo do "aqui e agora", na obrigação de sub existência e, quando consegue refletir um pouco, só enxerga o tenebroso passado a perscrutar lhe o presente. 
romance, então, estabelece uma crítica com o descaso com os imigrantes que leva a uma perversa exploração da dignidade humana. De acordo como o narrador, Jung, assim como muitos imigrantes, não conseguiu chegar realmente a urbe parisiense, já que não foram acolhidos por ela: "París es la ciudad a la que no han logrado llegar. Por eso, no es verdad que somos todos iguales. Esa pretensión enciclopedista francesa de la igualdad hoy es hipócrita. No somos todos iguales ni en la vida ni en la muerte" (GAMBOA, 2005, p. 240).

O romance tem seu ápice na noite em que, depois de um longo dia de trabalho, Esteban chega em casa e logo é chamado a comparecer urgente ao hospital porque Jung teria se acidentado. A enfermeira do hospital informa a Esteban que Jung havia se atirado da janela do seu quarto no sexto andar. Quando o trouxeram ao hospital ainda respirava, mas morreu antes de entrar para sala de cirurgia. Então, devido à ausência de familiares, foi pedido à Esteban para fazer o reconhecimento do corpo. Nesse momento Esteban, aturdido, indaga ao médico o que fez com que o amigo, após enfrentar tanta coisa para chegar à Europa, desistisse. O médico responde que todas as coisas difíceis que Jung deve ter vivido, juntamente a "su autoestima por el suelo, la indefensión y el miedo, todo eso lo debió llevar al estrés crónico y a la depresión" (GAMBOA, 2004, p. 350). O narrador comenta que, naquela época, essa doença não havia ainda ganhado um nome: "aún no había sido bautizado con el síndrome del inmigrante o síndrome de Ulises" (GAMBOA, 2004, p. 350).

\section{Considerações finais: a síndrome do imigrante ou a doença da memória}

Todos vuelven a la tierra en que nacieron; / al embrujo incomparable de su sol. / Todos vuelven al rincón de donde salieron: / donde acaso floreció más de un amor. / Bajo el árbol solitario del pasado, / cuántas veces nos ponemos a soñar / todos vuelven, por la ruta del recuerdo, / pero el tiempo del amor no vuelve más. / El aire, que trae en sus manos la flor del pasado, y su aroma de ayer, / nos dice muy quedo al oído su canto aprendido del atardecer; / nos dice, con voz misteriosa de cardo y de rosa, de luna y de miel, / que es santo el amor de la tierra, / que es triste la ausencia que deja el ayer. / Todos vuelven.

(Todos vuelven, Rubén Blades)

Santiago Gamboa evoca na obra El Síndrome de Ulises (2005) uma mensagem política: a denúncia frente ao descaso do poder pela situação em que os imigrantes vivem. Pessoas que, ao partirem rumo ao desconhecido em busca de um futuro mais alentador, acabam por ser excluídas e marginalizadas. Gamboa também desmitifica a utopia parisiense e mostra o perigo de abraçar esse "mal entendido" de que a França será para todos a terra da liberdade, da fraternidade e da igualdade (sem distinção de etnias, credos, nacionalidades, etc.). Na voz do narrador, vemos anunciada essa desilusão de que Paris "no era lo que él se esperaba (todo era viejo y decrépito), pero se podía vivir bien si uno era inteligente" (GAMBOA, 2004, p. 350). E ser inteligente, neste contexto, significa adaptar-se a todos os tipos de empregos, privações e humilhações, tornando-se mais duro e insensível frente as hostilidades sofridas, nas palavras do narrador, o sujeito deslocado: "Dejaba atrás una vieja piel, frágil, temerosa, y le daba paso a una nueva, más fuerte, la piel con la que debía encarar esta urbe cruel y alocada en la que todo el mundo debía armarse para no ser tragado y después escupido en algún maloliente sifón" (GAMBOA, 2004, p. 152).

Visualizamos, também, neste romance que os sentimentos de desamparo e de ausência de um vínculo dos imigrantes se agravam quando se trata de um exílio em condições ilegais, vivido em uma cidade grande, marcada pela pressa desenfreada da modernidade / pós-modernidade, que gera grande distanciamento emocional entre os indivíduos, isolando-os, cada vez mais, uns dos outros. A falta de acolhimento e a insegurança da clandestinidade geram uma enfermidade que, no desenrolar da trama de Gamboa, percebemos ter suas raízes na memória que está sufocada e não pode se expressar identitariamente. Além disso, como explica Said (2003), existe uma fratura incurável na situação de exílio, "para o exilado, os hábitos de vida, expressão 
ou atividade no novo ambiente ocorrem inevitavelmente contra o pano de fundo da memória dessas coisas em outro ambiente" (SAID, 2003, p. 59).

De acordo com Achugar (2006), a reivindicação de direitos de memória, pressupõe também uma reinvidicação de direitos de identidade, enfim, de direitos humanos. Por isso, não se deve escamotear 0 fato de que nesse embate entre memórias individuais e memórias que farão parte do acervo universal são várias as memórias que convivem e lutam entre si para construir uma memória coletiva, sendo que algumas imperam sobre outras. Assim, por meio do "caráter transitório das identificações dos sujeitos" (HALL, 2004, p. 13), surge a identidade do imigrante, o sujeito deslocado, expatriado e marginalizado. E como "as identidades são historicamente construídas, de acordo com aquilo que demandam o tempo e o espaço nos quais encontram realização" (HALL, 2004, p. 13), os imigrantes contemporâneos figurados na obra de Gamboa são Ulisses desprovidos do heroísmo e da dignidade de terem vivido aventuras e façanhas. São simplesmente tachados como ilegais, clandestinos, fantasmas, invisíveis (mão de obra barata, explorada e descartável); na análise de Edward Said: não podemos nos esquecer que no exílio "nada é seguro" (SAID, 2003, p. 51), já que por mais que tenham êxito, os exilados "sentem sua diferença" (SAID, 2003, p. 55), "como um tipo de orfandade" (SAID, 2003, p. 55). E, por isso, muitas vezes agarram-se a essa diferença e tentam bloquear o contato externo, insistem "no direito de se recusar a pertencer a outro lugar" (SAID, 2003, p. 55), correndo, portanto, o risco de padecer da síndrome de Ulisses, o apego à memória da terra natal, que se torna enfermiça e ilusória: "En las fiestas, com otros latinoamericanos, se entristecían escuchando la letra de Todos vuelven, de Rubén Blades" (GAMBOA, 2004, p. 18), momentos em que a sala de encontros de imigrantes "se impregnaba de silencio, un silencio que quería decir muchas cosas sencillas: recordamos, seguimos siempre, estamos allá, nos esperan" (GAMBOA, 2004, p. 18).

\section{Referências}

ACHOTEGUI, Joseba. "Migración y Crisis: el síndrome del inmigrante con estrés crónico y múltiple (Síndrome de Ulises)". In: ASMR (Avances en Salud Mental Relacional) Revista Internacional. Bilbao: Instituto de Psicoterapia, 2008.

ACHUGAR, Hugo. Planetas sem boca: Escritos efêmeros sobre arte, cultura e literatura. Trad. Lyslei Nascimento. Belo Horizonte: Ed. UFMG, 2006.

CASTIÑEIRA, Angel. "Naciones imaginadas. Identidad personal, identidad nacional y lugares de memoria". In: RESINA, Joan Ramón; WINTER, Ulrich (eds.). Casa encantada: Lugares de memoria en la España constitucional (1978-2004). Madrid / Frankfurt: Iberoamericana / Vervuert, 2005.

GAMBOA, Santiago. El síndrome de Ulises. Bogotá: Editorial Seix Barral, 2005.

HALBWACHS, Maurice. A memória coletiva. Trad. Beatriz Sidou. São Paulo: Ed. Centauro, 2006.

HALL, Stuart. A identidade cultural na PósModernidade. Rio de Janeiro, DP\&A Editora, 2004.

LACLAU, Ernesto. Emacipación y diferencia. Buenos Aires: Ariel, 1996.

REINOSO, Susana. "Reflejos del mal de Ulises". In: La Nación, Columna de Cultura, 10/11/2005. Disponível em: <http://www.lanacion.com.ar/754996reflejos-del-mal-de-ulises>. Acesso: 04/04/2014.

RICOEUR, Paul. La memoria, la historia, el olvido.Trad. Agustín Neira. Buenos Aires: Ed. FCE, 2000.

SAID, Edward W. "Reflexões sobre o exílio". In: Reflexões sobre o exílio: e outros ensaios. Trad. Pedro Maia Soares. São Paulo: Companhia das Letras, 2003, pp.46-60.

TORRES, Sônia. Nosotros in USA: literatura, etnografia e geografias de resistência. Rio de Janeiro: Jorge Zahar, 2001. 